\title{
Maternal Smoking and Smoking in Adolescents: A Prospective Community Study of Adolescents and Their Mothers
}

\author{
Roselind Lieb ${ }^{a}$ Andrea Schreier ${ }^{a}$ Hildegard Pfister $^{a}$ \\ Hans-Ulrich Wittchen ${ }^{a, b}$ \\ a Clinical Psychology and Epidemiology Unit, Max Planck Institute of Psychiatry, Munich, and \\ bInstitute of Clinical Psychology and Psychotherapy, Technical University of Dresden, Dresden, Germany
}

\section{Key Words}

Maternal smoking $\cdot$ Smoking in adolescence $\cdot$ Nicotine dependence $\cdot$ Patterns of smoking

\begin{abstract}
The associations between maternal smoking and nicotine dependence and patterns of smoking and nicotine dependence in offspring were examined in a large community-based sample of adolescents. Data were derived from baseline and 4-year follow-up assessments of 938 respondents aged 14-17 years at the outset of the Early Developmental Stages of Psychopathology (EDSP) study, a prospective-longitudinal community study of adolescents and young adults and their parents respectively. Smoking and nicotine dependence in respondents were assessed using the Munich Composite International Diagnostic Interview (DSM-IV algorithms). Diagnostic information about smoking behavior in mothers was collected by independent direct diagnostic interviews with the mothers. In comparison to children of non- or occasionally smoking mothers, children of regularly smoking and nicotine-dependent mothers had higher probabilities of using tobacco as well as of developing nicotine dependence. For all ages under consideration, survival analyses revealed a higher cumulative lifetime risk of
\end{abstract}

\section{KARGER}

Fax +41613061234

E-Mail karger@karger.ch

www.karger.com
(C) 2003 S. Karger AG, Basel

1022-6877/03/0093-0120\$19.50/0

Accessible online at:

www. karger.com/ear regular smoking and nicotine dependence among these children. Maternal smoking during pregnancy seems to represent an additional risk for these outcomes in children, specifically with regard to the risk of developing nicotine dependence. Associations were comparable for sons and daughters. Our findings show that maternal smoking predicts escalation of smoking, development of nicotine dependence, and stability of smoking behavior in children. Implications for specific intervention and prevention efforts are discussed.

Copyright $@ 2003$ S. Karger AG, Basel

\section{Introduction}

During recent decades, a vast number of studies investigated the question of how maternal substance use behavior influences substance use behavior in their offspring. A substantial number of studies showed that the offspring of mothers with problem drinking have an increased risk of developing problems with alcohol [1-8] as well as problems with other psychotropic substances [4, 5, 9-13]. Nicotine is the most often used psychotropic substance among women [14-16] followed by alcohol. Considerably research has focused on the relationship between maternal smoking during pregnancy and behavioral distur- 
bances [17-25], physical and respiratory health [26, 27] as well as neurobiological development in children [28, 29].

In contrast, considerably fewer studies have systematically examined the effect of maternal smoking - either during pregnancy or not - on differential aspects of the development of substance use behavior, specifically smoking behavior, in children. Most studies in this area addressed the question of whether maternal smoking influences smoking initiation in children during early or middle adolescence [21,30-41], while relatively little attention has been given to the extent to which maternal smoking influences the child's smoking behavior over time, such as transition into higher use categories (heavy smoking, nicotine dependence) or the probability of smoking cessation [42-44]. Although the findings of these studies suggest that maternal smoking increases the risk not only for smoking initiation during adolescence but also for a less favorable course of smoking behavior over time, several methodological limitations, such as predominant use of self-report questionnaires, child's report on maternal smoking, use of selective samples, or exclusive use of cross-sectional data, restrain the significance of these reports. Notably, all previous studies did not distinguish between different 'stages' of smoking and nicotine dependence in evaluating such mother-child associations. Distinguishing between stages of smoking behavior, however, seems to be of particular importance, as recent research has shown that risk factors predicting smoking initiation may be different from those predicting the subsequent course of smoking behavior [45-47]. As far as we are aware, there is no study available that evaluated the influence of maternal smoking on smoking behavior in children by considering not only smoking but also the diagnosis of nicotine dependence in both mothers and children.

This article examines the mother-child associations of smoking and nicotine dependence in a prospectively assessed representative community sample of adolescents for whom diagnostic information about smoking and nicotine dependence in both mothers and children was collected by independent diagnostic interviews. Specifically, we examine the association between regular smoking and nicotine dependence in mothers and various aspects of smoking behavior and nicotine dependence (prevalences, age at first onset, progression, cessation) in the children. The effect of maternal smoking during pregnancy on children's smoking behavior was additionally explored.

Maternal Smoking and Smoking in

Adolescents

\section{Methods}

\section{Design}

The data presented stem from the Early Developmental Stages of Psychopathology (EDSP) project, a prospective-longitudinal study designed to collect data on the prevalence and incidence, familial and other risk factors, comorbidity, and course of mental disorders in a representative sample of originally 3,021 subjects aged 14-24 years. The study consists of a baseline investigation and 2 follow-up investigations. The parents of the baseline 14- to 17-year-olds were additionally assessed in a separate parent survey.

Sample

The EDSP builds on a random population sample from the 1994 government population registries of residents in Munich with an expected age range for the sampled subjects between 14 and 24 at the time of the baseline interview in 1995. Details about the sampling, representativeness, and sociodemographic characteristics of the whole EDSP sample have been reported elsewhere [48, 49]. At baseline, the response rate for the study sample of 14- to 17-year-olds (the 'younger cohort') was $74.3 \%$. Two follow-up assessments were completed after the initial baseline investigation, covering an overall period of 3-4 years. The first follow-up study (T1) was conducted an average of 19.7 (range 15-25.6) months and the second follow-up study (T2) an average of 42 (range 34-50) months after the baseline investigation. The response rate for the baseline 14- to 17-year-olds was $88 \%$ at $\mathrm{T} 1$ and $84 \%$ at $\mathrm{T} 2$.

In the parent survey, direct diagnostic interviews were conducted with the parents of this younger cohort. As we were interested not only in familial psychopathology but also in early developmental information about the respondents, primarily the mothers were interviewed. Fathers were interviewed only if the mother was not available (dead or could not be located). The parents of 1,053 adolescents were interviewed directly (in 1,026 cases the mother, in 27 cases the father; response rate $86 \%$ ). Nonresponse in parents was predominantly due to refusal to participate $(12.9 \%)$, researchers' failure to contact parents $(0.7 \%)$, and parents' lack of time $(0.5 \%)$ [49]. The results reported in this article are based on those at baseline 14- to 17 -years-old who completed the whole study period and whose mothers participated in the parent survey $(\mathrm{n}=938)$. These respondents represent the children in this report.

\section{Diagnostic Assessment of Respondents}

Diagnostic assessments at baseline and the 2 follow-up investigations (of the respondents) were based on the computer-assisted version of the Munich Composite International Diagnostic Interview, which allows for the assessment of symptoms, syndromes, and diagnoses of 48 mental disorders according to the DSM-IV along with information about onset, duration, severity, and psychosocial impairment (M-CIDI) [50]. Diagnostic findings were obtained using the M-CIDI/DSM-IV algorithms. Reliability and validity of the M-CIDI have been reported [48, 51-53]. For all assessments the M-CIDI was supplemented by a separate respondent's booklet that included several scales and questionnaires to assess psychological constructs relevant to the study. All interviews were administered by highly trained clinical interviewers. A detailed overview of the constructs and assessment methods has been presented $[49,54,55]$. At baseline, the lifetime version of the M-CIDI was used. At each of the follow-up assessments, the M-CIDI interval version, which refers to the time period between the last interview and the present, was applied. For 
the study sample considered in this report, the complete follow-up status T0-T2 was assessed from the aggregation of information obtained from the $\mathrm{T} 1$ and $\mathrm{T} 2$ interviews.

\section{Diagnostic Assessment of Mothers}

In the parent survey, the mothers of the younger cohort were independently assessed with the M-CIDI, providing direct diagnostic information about DSM-IV substance use and other mental disorders. Interviewers were blind to the diagnostic findings of the respective index proband. The parent M-CIDI was supplemented by 2 additional modules that provided (a) family history data for the noninterviewed parent and other family members of the index proband (not used in this report), and (b) detailed information about the offspring's perinatal, psychological and somatic conditions in infancy and early childhood.

\section{Smoking Measures}

For mothers and offspring, all diagnostic information concerning smoking behavior was collected in the M-CIDI nicotine section [for details, see 56, 57]. Although the M-CIDI defines tobacco products as cigarettes, cigars, pipes, snuff or chew, almost all mothers and respondents $(99 \%)$ reported cigarettes as the only tobacco product used. Therefore, the terms smoking and tobacco use are used synonymously in this article.

\section{Children's Smoking Status}

Four categories were used to describe smoking status in children: (1) 'non-smoking' defines children who never used any tobacco product during their life; (2) 'occasional smoking' defines children who experimented with tobacco products but never smoked daily for a period of at least 4 weeks; (3) 'regular smoking' defines children who smoked daily for a period of at least 4 weeks, and (4) 'DSM-IV nicotine dependence' defines children who experienced 3 of the 7 symptoms for DSM-IV nicotine dependence within the same 12-month time period.

Maternal Smoking Status

Maternal smoking behavior was categorized as follows: (1) 'non/ occasional smoking' defines mothers who stated that they had either never used any tobacco product at all or tried some tobacco product at least once but never smoked regularly (NON/OCC mothers); (2) 'non-dependent regular smoking' defines mothers who reported having smoked cigarettes daily for a period of at least 4 weeks during their life, but who never fulfilled DSM-IV lifetime criteria for nicotine dependence (REG mothers), and (3) 'nicotine dependence' defines mothers who reported regular smoking and who met DSMIV lifetime criteria for nicotine dependence (NICDEP mothers). For the analyses concerning maternal smoking during pregnancy, the following categories were used: (1) 'non/occasional smoking', as above (NON/OCC mothers); (2) 'non-pregnancy smoking' defines mothers who reported lifetime regular smoking but who never smoked during pregnancy (PREG- mothers), and (3) 'pregnancy smoking' defines mothers who reported lifetime regular smoking and who smoked during pregnancy (PREG+ mothers). Smoking behavior during pregnancy was assessed within the direct parent interview by asking how often the mother of the proband had smoked during pregnancy: never; 1-2 times; 3-5 times; 6-100 times; every 2 weeks; weekly, or almost daily.

\section{Statistical Analyses}

Data were weighted to consider different sampling probabilities as well as systematic non-response at baseline. Analyses were performed using the Stata software package [58] and applying the Huber-White sandwich matrix for weighted data [59]. To estimate the associations between maternal smoking status and diagnostic outcome in offspring, logistic regressions with odds ratios (ORs) were used [60]. For the analyses of overall association between maternal smoking status and frequency of smoking in children, cumulative logistic regressions using cumulative odds ratios (CUMOR) were used [61]. Age at onset characteristics for regular smoking and nicotine dependence were examined with the Kaplan-Meier method [62]. Differences between curves were assessed with hazard ratios (HR) from the stratified Cox model for discrete time [63]. The interaction terms age $\times$ maternal smoking were added to the model when the proportional hazards assumption was violated. An interaction of age $x$ maternal smoking with an $\mathrm{HR}$ of $<1$ indicates that children of smoking mothers have an earlier onset, e.g. of nicotine dependence, dependent on the fact that they report the outcome under consideration. For all age at onset analyses, information from all 3 waves (considering age at first onset of the respective outcome) was used. Sex and age of the children were controlled by including them as independent variables in the respective models. To examine possible gender differences in the effects of maternal smoking, all associations were tested for interaction with the gender of the offspring. Throughout the article, a $p$ value of $<0.05$ is considered as statistically significant.

\section{Results}

\section{Lifetime Prevalence of Smoking and Nicotine \\ Dependence in Mothers and Children at Baseline}

About half of the mothers reported that they had never smoked during their lifetime or that they had never used tobacco on a daily basis for a period of at least 4 weeks (NON/OCC mothers $46.3 \%$; table 1). A total of $53.7 \%$ of the mothers reported that they had at some point smoked daily for at least 4 weeks. About one third of the mothers (35.3\%) reported non-dependent regular smoking (REG mothers), and about one fifth (18.4\%) fulfilled DSM-IV lifetime criteria for nicotine dependence (NICDEP mothers). At baseline, $34.0 \%$ of the respondents reported that they had never used any tobacco product during their lifetime. About half of the study sample (45.7\%) reported occasional smoking, about one fifth of the sample were classified as regular smokers $(20.2 \%)$, and $11.4 \%$ of the offspring were diagnosed as fulfilling DSM-IV lifetime criteria for nicotine dependence. At baseline, female respondents had a lower risk of shifting towards occasional and regular smoking compared to male respondents (CUMOR females vs. males $=0.73 ; 95 \% \mathrm{CI}=0.56-0.95$ ). No gender difference could be observed at baseline regarding nicotine dependence (OR females vs. males = $1.00 ; 95 \% \mathrm{CI}=0.62-1.62$ ). 
Table 1. Lifetime prevalence rates of smoking behavior in mothers and children at baseline

\begin{tabular}{|c|c|c|c|c|}
\hline & \multicolumn{4}{|c|}{ Frequency ${ }^{1}$} \\
\hline & $\mathrm{N}$ & $\mathrm{Nw}$ & $\% \mathrm{w}$ & $95 \% \mathrm{CI}^{2}$ \\
\hline \multicolumn{5}{|l|}{ Maternal smoking status } \\
\hline Non/occasionally smoking (NON/OCC) & 429 & 428 & 46.3 & $42.8-49.8$ \\
\hline Non-dependent regularly smoking (REG) & 332 & 326 & 35.3 & $32.0-38.7$ \\
\hline Nicotine dependence (NICDEP) & 177 & 170 & 18.4 & $15.8-21.2$ \\
\hline \multicolumn{5}{|l|}{ Children's smoking status (baseline) } \\
\hline \multicolumn{5}{|l|}{ Non-smoking } \\
\hline Males & 154 & 136 & 30.0 & $25.8-34.6$ \\
\hline Females & 175 & 179 & 37.9 & $33.2-42.8$ \\
\hline Total & 329 & 314 & 34.0 & $30.8-37.4$ \\
\hline \multicolumn{5}{|l|}{ Occasional smoking } \\
\hline Males & 239 & 220 & 48.7 & $43.8-53.6$ \\
\hline Females & 204 & 202 & 42.8 & $38.0-47.8$ \\
\hline Total & 443 & 422 & 45.7 & $42.2-49.2$ \\
\hline \multicolumn{5}{|l|}{ Regular smoking (w/wo nicotine dependence) } \\
\hline Males & 85 & 96 & 21.3 & $17.4-25.8$ \\
\hline Females & 81 & 91 & 19.3 & $15.5-23.7$ \\
\hline Total & 166 & 187 & 20.2 & $17.5-23.4$ \\
\hline \multicolumn{5}{|l|}{ DSM-IV nicotine dependence } \\
\hline Males & 45 & 51 & 11.2 & $8.3-15.0$ \\
\hline Females & 45 & 55 & 11.6 & $8.6-15.6$ \\
\hline Total & 90 & 106 & 11.4 & $9.2-14.1$ \\
\hline \multicolumn{5}{|c|}{$\begin{array}{l}1 \mathrm{~N}=\text { Unweighted number }(\mathrm{n}=938) ; \mathrm{Nw}=\text { weighted number }(\mathrm{n}=924) ; \% \mathrm{w}=\text { weightec } \\
\text { percentage; } \mathrm{w} / \mathrm{wo}=\text { with/without. } \\
2 \text { The } 95 \% \text { confidence interval refers to the weighted numbers. }\end{array}$} \\
\hline
\end{tabular}

Table 2. Lifetime prevalence rates of smoking and nicotine dependence according to maternal smoking status at baseline

\begin{tabular}{|c|c|c|c|c|c|c|c|c|c|c|c|c|}
\hline \multirow{4}{*}{$\begin{array}{l}\text { Children's smoking } \\
\text { behavior at baseline }\end{array}$} & \multicolumn{6}{|c|}{ Maternal smoking status } & \multirow{2}{*}{\multicolumn{2}{|c|}{$\begin{array}{l}\text { REG vs. } \\
\text { NON/OCC } \\
\end{array}$}} & \multirow{2}{*}{\multicolumn{2}{|c|}{$\begin{array}{l}\text { NICDEP vs. } \\
\text { NON/OCC }\end{array}$}} & \multirow{2}{*}{\multicolumn{2}{|c|}{$\begin{array}{l}\text { NICDEP vs. } \\
\text { REG }\end{array}$}} \\
\hline & \multirow{2}{*}{\multicolumn{2}{|c|}{$\begin{array}{l}\text { NON/OCC } \\
(\mathrm{n}=429)\end{array}$}} & \multirow{2}{*}{\multicolumn{2}{|c|}{$\begin{array}{l}\text { REG } \\
(\mathrm{n}=332)\end{array}$}} & \multirow{2}{*}{\multicolumn{2}{|c|}{$\begin{array}{l}\text { NICDEP } \\
(\mathrm{n}=177)\end{array}$}} & & & & & & \\
\hline & & & & & & & \multirow{2}{*}{$\begin{array}{l}\text { CUMOR/ } \\
\text { OR }\end{array}$} & \multirow[t]{2}{*}{$95 \% \mathrm{CI}$} & \multirow{2}{*}{$\begin{array}{l}\text { CUMOR/ } \\
\text { OR }\end{array}$} & \multirow[t]{2}{*}{$95 \% \mathrm{CI}$} & \multirow{2}{*}{$\begin{array}{l}\text { CUMOR/ } \\
\text { OR }\end{array}$} & \multirow[t]{2}{*}{$95 \% \mathrm{CI}$} \\
\hline & $\mathrm{n}$ & $\% \mathrm{w}$ & $\mathrm{n}$ & $\% w$ & $\mathrm{n}$ & $\% \mathrm{w}$ & & & & & & \\
\hline Non-smoking & 177 & 40.2 & 91 & 25.3 & 61 & 35.2 & & & & & & \\
\hline Occasional smoking & 199 & 44.1 & 161 & 48.3 & 83 & 44.9 & & & & & & \\
\hline \multicolumn{13}{|l|}{ Regular smoking } \\
\hline (w/wo nicotine dependence) & 53 & 15.7 & 80 & 26.5 & 33 & 19.9 & $1.93^{*}$ & $1.43-2.60$ & 1.38 & $0.94-2.02$ & 0.72 & $0.48-1.06$ \\
\hline Nicotine dependence & 32 & 9.9 & 41 & 13.7 & 17 & 11.1 & 1.50 & $0.89-2.54$ & 1.18 & $0.57-2.46$ & 0.79 & $0.38-1.63$ \\
\hline
\end{tabular}

$\mathrm{n}=$ Number; $\% \mathrm{w}=$ weighted percentages; $\mathrm{OR}=$ odds ratio; $\mathrm{CI}=$ confidence interval; $\mathrm{CUMOR}=$ cumulative odds ratio adjusted for age and gender effects; NON/OCC $=$ non-/occasionally smoking mothers; $\mathrm{REG}=$ non-dependent regularly smoking mothers; NICDEP $=$ nicotine-dependent mothers. $* \mathrm{p}<0.05$.

\section{Baseline Prevalence of Smoking and Nicotine \\ Dependence in Children according to Maternal \\ Smoking Status}

Assuming that there is a continuation of severity according to smoking status from no use, occasional to regular use, table 2 shows that, at baseline, children of
REG mothers reveal a significant shift towards higher smoking categories. No such result was found for children of NICDEP mothers. At baseline, however, no significant associations were found between maternal smoking status (either dependent or not) and nicotine dependence in children. All associations were additionally tested for interac- 
Table 3. Changes in smoking patterns and nicotine dependence during the 4-year follow-up interval according to maternal smoking status

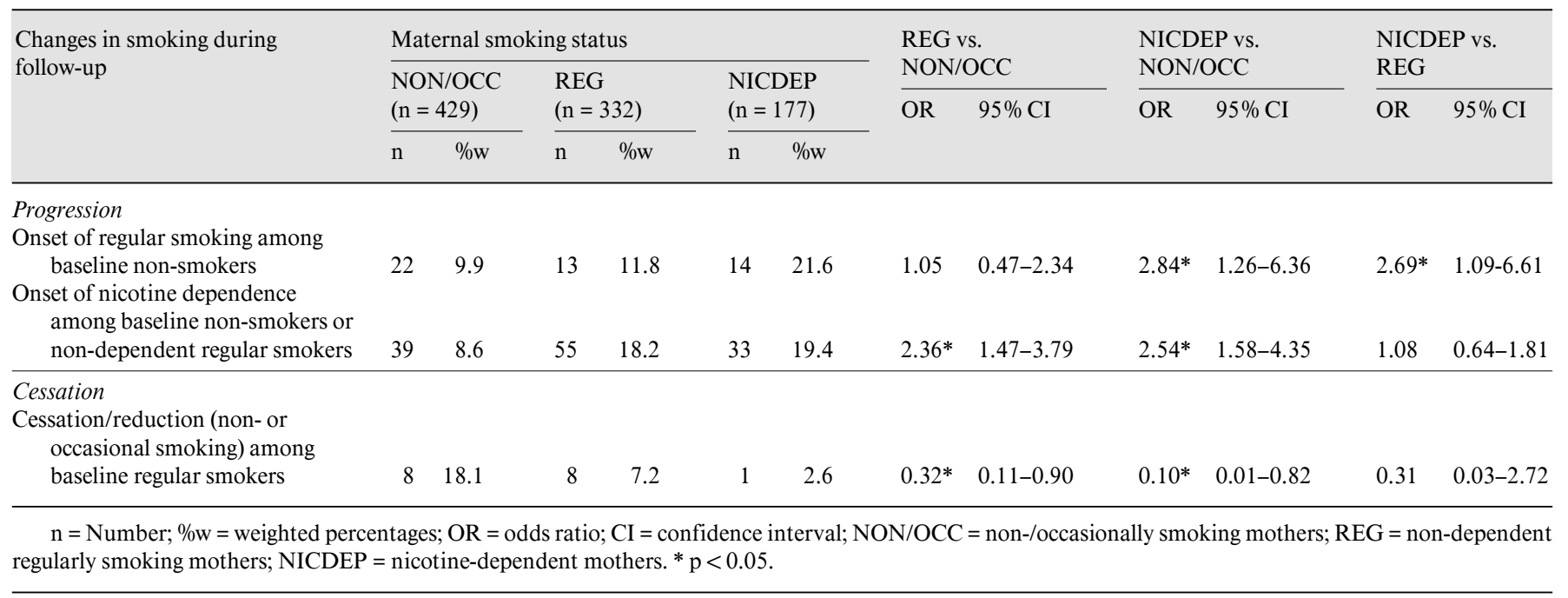

tion with the gender of the child. No significant effects were found, indicating that associations are comparable for sons and daughters.

\section{Progression and Reduction of Smoking in Offspring by Maternal Smoking Behavior}

Table 3 reports the findings on the change over time in children's smoking status according to maternal smoking status. First, it was examined whether respondents with smoking mothers have an elevated odds of starting regular smoking or developing nicotine dependence during the follow-up period of 4 years when compared to the outcomes of those without smoking mothers. Among baseline non-smokers, the children of NICDEP mothers were more likely to become at least regular smokers $(21.6 \%)$ when compared to the children of NON/OCC mothers (9.9\%) and also when compared to the children of REG mothers $(11.8 \%)$. The offspring of both REG and NICDEP mothers, however, were more likely to develop nicotine dependence during follow-up when compared to the children of NON/OCC mothers (19.4 and 18.2 vs. $8.6 \%)$. Testing all the associations for interaction with the gender of the children again revealed no significant effects.

Considering, then, the other direction of change, i.e., cessation and reduction of smoking behavior during the 4-year follow-up period (table 3), the children of NON/ OCC mothers had a higher probability of moving from regular use at baseline to non- or occasional use during follow-up when compared to the children of REG and NICDEP mothers (18.1 vs. 7.2 and 2.6\%). Although the respective rates were considerably lower in the children of NICDEP mothers when compared to the children of REG mothers, rates did not differ significantly.

\section{Smoking Behavior in Mothers and Age at Onset Characteristics for Regular Use and Nicotine \\ Dependence}

Figure 1 shows the age-specific cumulative probability of developing regular smoking in children according to maternal smoking status. In all 3 groups, the rates begin to increase after age 11 years, but the increase is steeper in the children of REG and NICDEP mothers. The peak incidence period for these offspring is between the ages of 13 and 16 years; then the rates plateau after age 19 . By this age more than $50 \%$ of the children of REG and NICDEP mothers reported regular smoking. For the group of children of NON/OCC mothers, the rates increase more slowly and then plateau after age 19 years at a lower level (37\%). Overall hazard rates for the children of REG mothers $(\mathrm{HR}=1.64 ; 95 \% \mathrm{CI}=1.31-2.04)$ and NICDEP mothers $(\mathrm{HR}=1.57 ; 95 \% \mathrm{CI}=1.20-2.04)$ were significantly different from those of the children of NON/OCC mothers. No differences were found between children of REG and NICDEP mothers, and no effects were found for the interactions of age $\times$ REG/NICDEP mother.

Figure 2 shows the children's age-specific cumulative incidence rates for DSM-IV nicotine dependence by maternal smoking status. For all 3 groups, the rates increase around age 13 years, again with steeper increases in the children of REG and NICDEP mothers. For the children of both REG and of NICDEP mothers, the curves in- 
Fig. 1. Age at onset of regular smoking according to maternal smoking status: NON/ $\mathrm{OCC}=$ non-/occasionally smoking mothers; REG $=$ non-dependent regularly smoking mothers; NICDEP = nicotine-dependent mothers.

Fig. 2. Age at onset of nicotine dependence according to maternal smoking status: NON/ $\mathrm{OCC}=$ non-/occasionally smoking mothers; REG $=$ non-dependent regularly smoking mothers; NICDEP = nicotine-dependent mothers.
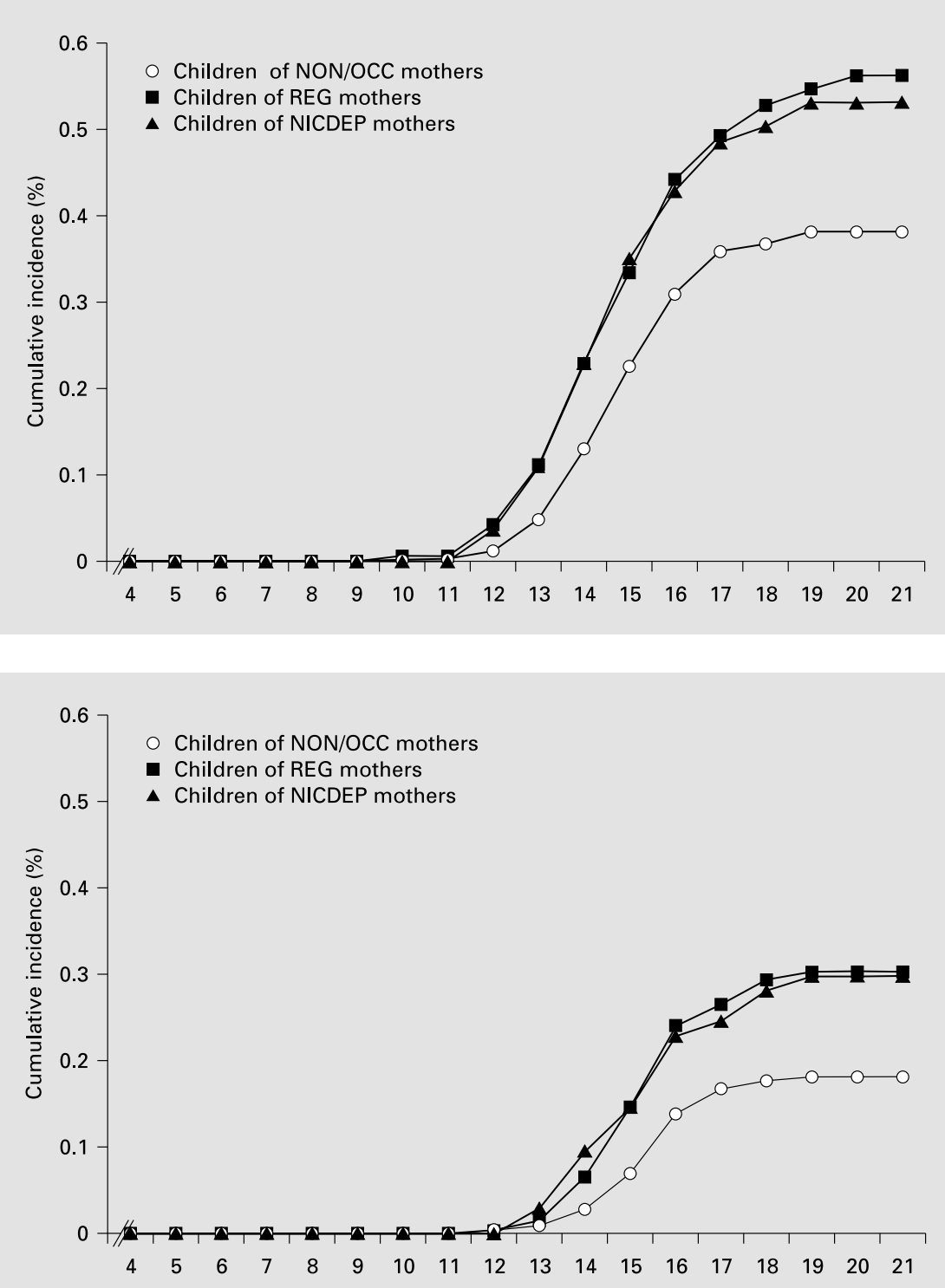

crease until age 19 years and then plateau at a relatively high level (30\%). For the children of NON/OCC mothers, the curve also begins to increase at age 13 years, but plateaus at a lower level (18\%) at age 17 . The overall hazard rates for the children of REG mothers (HR $=1.77 ; 95 \%$ $\mathrm{CI}=1.28-2.45)$ and NICDEP mothers $(\mathrm{HR}=1.76 ; 95 \%$ $\mathrm{CI}=1.20-2.56)$ were significantly different from those of the children of NON/OCC mothers. Again, no differences were found between the children of REG and NICDEP mothers, and no effects were found for the interactions of age $\times$ REG/NICDEP mother.

Maternal Smoking and Smoking in Adolescents
Maternal Smoking during Pregnancy and Smoking Behavior in Children

At baseline, the children of PREG- and PREG+ mothers reported a shift towards higher smoking categories when compared to the children of NON/OCC mothers (table 4). In addition, the children of PREG+ mothers had a higher risk than did the children of PREG- mothers.

At baseline the children of PREG+ mothers reported a significantly higher lifetime prevalence rate of nicotine dependence when compared to both the children of PREG- mothers (20.6 vs. 9.9\%; OR $=2.54 ; 95 \% \mathrm{CI}=$ 1.41-4.60) and the children of NON/OCC mothers (20.6

Eur Addict Res 2003;9:120-130 
Table 4. Baseline prevalence of smoking and nicotine dependence according to maternal smoking status during pregnancy

\begin{tabular}{|c|c|c|c|c|c|c|c|c|c|c|c|c|}
\hline \multirow{4}{*}{$\begin{array}{l}\text { Children's smoking } \\
\text { behavior at baseline }\end{array}$} & \multicolumn{6}{|c|}{ Maternal smoking status } & \multirow{2}{*}{\multicolumn{2}{|c|}{$\begin{array}{l}\text { PREG- vs. } \\
\text { NON/OCC }\end{array}$}} & \multirow{2}{*}{\multicolumn{2}{|c|}{$\begin{array}{l}\text { PREG+ vs. } \\
\text { NON/OCC }\end{array}$}} & \multirow{2}{*}{\multicolumn{2}{|c|}{$\begin{array}{l}\text { PREG+ vs. } \\
\text { PREG- }\end{array}$}} \\
\hline & \multirow{2}{*}{\multicolumn{2}{|c|}{$\begin{array}{l}\text { NON/OCC } \\
(\mathrm{n}=429)\end{array}$}} & \multirow{2}{*}{\multicolumn{2}{|c|}{$\begin{array}{l}\text { PREG- } \\
(\mathrm{n}=340)\end{array}$}} & \multirow{2}{*}{\multicolumn{2}{|c|}{$\begin{array}{l}\text { PREG+ } \\
(\mathrm{n}=169)\end{array}$}} & & & & & & \\
\hline & & & & & & & \multirow{2}{*}{$\begin{array}{l}\text { CUMOR/ } \\
\text { OR }\end{array}$} & \multirow[t]{2}{*}{$95 \% \mathrm{CI}$} & \multirow{2}{*}{$\begin{array}{l}\text { CUMOR/ } \\
\text { OR }\end{array}$} & \multirow[t]{2}{*}{$95 \% \mathrm{CI}$} & \multirow{2}{*}{$\begin{array}{l}\text { CUMOR/ } \\
\text { OR }\end{array}$} & \multirow[t]{2}{*}{$95 \% \mathrm{CI}$} \\
\hline & $\mathrm{n}$ & $\% w$ & $\mathrm{n}$ & $\% w$ & $\mathrm{n}$ & $\% w$ & & & & & & \\
\hline Never & 177 & 40.2 & 109 & 31.0 & 43 & 24.1 & & & & & & \\
\hline Occasional & 199 & 44.1 & 172 & 50.9 & 72 & 39.5 & & & & & & \\
\hline At least regular smoking & 53 & 15.7 & 59 & 18.1 & 54 & 36.4 & $1.37 *$ & $1.03-1.83$ & $2.85^{*}$ & $1.88-4.34$ & $2.08^{*}$ & $1.37-3.15$ \\
\hline Nicotine dependence & 32 & 9.9 & 29 & 8.9 & 29 & 20.6 & 0.94 & $0.54-1.65$ & $2.54^{*}$ & $1.41-4.60$ & $2.71^{*}$ & $1.46-5.03$ \\
\hline
\end{tabular}

$\mathrm{n}=$ Number; $\% \mathrm{w}=$ weighted percentages; $\mathrm{OR}=$ odds ratio; $\mathrm{CI}=$ confidence interval; NON/OCC = non-/occasionally smoking mothers $(8$ mothers from this group reported having smoked during pregnancy); PREG- = regularly smoking mothers who did not smoke during pregnancy; PREG+ = regularly smoking mothers who smoked during pregnancy: more than half (57.9\%) of these mothers reported that they smoked almost daily; $5.9 \%$ weekly; $5.9 \%$ every 2 weeks; $15.4 \%$ 6-10 times; $7.1 \% 3-5$ times, and 7.6\% 1-2 times. ${ }^{*} \mathrm{p}<0.05$.

vs. $8.9 \%$; OR $=2.71 ; 95 \% \mathrm{CI}=1.46-5.03)$. The age-specific cumulative probability of developing nicotine dependence in the children according to maternal smoking status during pregnancy was then analyzed. Here, the overall hazard rates of the children of PREG+ mothers were found to be significantly different from those of the children of NON/OCC mothers $(\mathrm{HR}=2.69 ; 95 \% \mathrm{CI}=$ 1.91-3.79) and from those of the children of PREGmothers $(\mathrm{HR}=1.97 ; 95 \% \mathrm{CI}=1.40-2.76)$. Hazard rates for the children of PREG- mothers did not differ from those for the offspring of NON/OCC mothers ( $\mathrm{HR}=1.37$; $95 \% \mathrm{CI}=0.98-1.92)$. No differences were found between sons and daughters, and no effects were found for the interactions of age $\times$ PREG+/PREG- mother.

\section{Discussion}

The goal of this study was to explore the effects of maternal smoking on various stages of smoking behavior in their children. As far as we are aware, this study is the first to examine cross-sectionally as well as prospectively the influence of maternal smoking on smoking behavior in the children by using a representative community sample and by considering not only smoking, but also the diagnosis of DSM-IV nicotine dependence in both mothers and children using identical assessment instruments.

The strengths of the study include: (1) exploration of mother-child associations in a representative community sample, unaffected by potential selection bias; (2) the focus on a sample of adolescents who were young enough at baseline so that the majority had not yet developed regular use or nicotine dependence, thus the effects of maternal smoking on smoking onset and progression patterns could be examined prospectively and longitudinally; (3) standardized symptom and diagnostic assessment of smoking behavior and DSM-IV nicotine dependence in both mothers and children, and (4) independent diagnostic assessments of mothers and children, thus excluding informant bias.

Limitations of the study include the following: (1) Data on maternal smoking during pregnancy were based solely on retrospective maternal reports. It is quite possible that, as pregnancies had occurred about 14-17 years earlier, the data could be biased by recall or by underreporting. (2) Not all respondents had passed through the entire risk period for onset of regular smoking or nicotine dependence, thus the results cannot yet be considered as robust. However, the inclusion of 'false-negative' cases (i.e., cases that have not yet developed the smoking outcomes) probably resulted in an underestimation rather than an overestimation of associations. (3) These findings only apply to adolescents and young adults, no data are available about the dynamics after the age of 28 years.

\section{Maternal Smoking and Stages of Smoking in Children}

Our baseline data combined with the cumulative follow-up data demonstrate that the children of smoking mothers tend to have an increased risk of smoking more during adolescence compared to the children of non-/ occasionally smoking mothers. By and large, these findings are in line with previous studies [37, 38, 64, 65]. It is noteworthy that, at baseline, we have not yet been able to demonstrate an effect of maternal smoking on nicotine dependence in children. However, such an effect emerged impressively during the 4-year follow-up period: the chil- 
dren of at least regularly smoking mothers reported not only higher incidence rates of regular smoking, but also considerably higher incidence rates of nicotine dependence. We suspect that this effect was not found at baseline because the children had not yet passed through the entire risk period for onset of nicotine dependence. The effect of maternal smoking on smoking behavior in children is further demonstrated by our prospective findings concerning the offspring's reduction and progression of smoking during the 4-year follow-up interval. Compared to the offspring of non-/occasionally smoking mothers, the children of smoking mothers are not only more likely to develop a more malignant pattern of smoking, but also they are less likely to quit or to reduce smoking. Similar results have been reported by $\mathrm{Zhu}$ et al. [44], who found that maternal smoking predicts continued smoking among adolescents. Our results strengthen these previous findings. However, for the first time, the present study uses prospectively assessed data that have been collected in a representative community sample and also include nicotine dependence in the child as an outcome.

\section{Onset of Smoking}

Although the age at onset findings demonstrate that maternal smoking increases the risk for first onset of regular smoking and nicotine dependence in children, no evidence was found that maternal smoking additionally increases the risk of beginning regular smoking earlier or of having an earlier onset of nicotine dependence. According to these findings, maternal smoking does not seem to affect the age at initiation of smoking behavior in children, but rather the early course in terms of developing regular smoking and nicotine dependence. This finding indicates that non-familial factors, e.g., peer group influences, may play a more important role than maternal smoking in the age of first smoking.

\section{Maternal Smoking vs. Maternal Nicotine Dependence}

Unlike previous researchers, we assessed both maternal non-dependent smoking and maternal nicotine dependence. This approach allowed us to study possible differential effects of these various smoking patterns in mothers. According to our results, it does not seem to be of great importance whether the mother smokes regularly or meets DSM-IV criteria for nicotine dependence, as the effects on different smoking outcomes in the child were in almost all cases similar between these 2 groups. The exception was that the children of nicotine-dependent mothers were at a higher risk for onset of regular smoking during the follow-up period when compared to the chil- dren of both non-/occasionally smoking and non-dependent smoking mothers. However, when combining baseline and follow-up data in the survival analyses, the children of both non-dependent regularly smoking mothers and nicotine-dependent mothers are at a higher risk of developing regular smoking when compared to the children of non-/occasionally smoking mothers. As no previous study has examined nicotine dependence in mothers, there is a need of further studies to replicate this finding.

\section{Maternal Smoking during Pregnancy}

Distinguishing regularly smoking mothers who also smoked during pregnancy from those who never smoked during pregnancy revealed that both are associated with a higher risk in the children of shifting towards occasional and regular smoking. With this result we confirmed previous findings that maternal smoking during pregnancy influences smoking behavior in children [35, 37, 40, 41]. Trying, then, to disentangle the effects of pregnancy and non-pregnancy smoking, we found that, although both conditions are associated with higher smoking rates in the children, maternal smoking during pregnancy seems to add an additional risk to the smoking behavior of the children. However, with respect to nicotine dependence as an outcome in the offspring, we found a somewhat different picture. Our baseline as well as our cumulative age-atonset data revealed higher rates of nicotine dependence in the children of mothers who smoked during pregnancy compared to the children of both non-smoking mothers and those who did not smoke during pregnancy, while no effect could be demonstrated for no maternal smoking during pregnancy. Thus, an elevated risk in the children of developing nicotine dependence seems mainly to pertain to the children of mothers who smoked during pregnancy.

\section{Differences in Associations between Sons and Daughters}

Although we have found a main effect that, at baseline, sons had a higher risk of shifting towards occasional and regular smoking when compared to daughters, our findings revealed no evidence for gender differences in mother-child associations of smoking. Our findings are consistent with those of Pederson et al. [38], but some other researchers have reported a stronger association between maternal smoking and child's smoking behavior for girls than for boys [33, 37, 40, 66]. However, it has to be mentioned that the stratified analyses in these studies should be viewed with caution inasmuch as they did not test for 
effects within the stratified models. As to date no other study has examined the possible gender-specific motherchild associations by testing for interaction effects, our results are not directly comparable with previous findings. In any case, our findings suggest that the impact of maternal smoking seems to be comparable for sons and daughters.

\section{Explanations}

The observed mother-child associations might be explained by several mechanisms, such as genetic [for review, see 67] and environmental factors [for review, see 68]. Our results argue for an overall mother-child transmission of smoking behavior, and lead to the conclusion that maternal smoking during pregnancy adds an additional risk specifically to the development of nicotine dependence. This increased risk suggests that in utero exposure to nicotine may influence the developing brain of the fetus and, thus, predispose the child's brain to subsequent addictive influences $[35,36]$. However, it is also conceivable that this observed effect of maternal smoking during pregnancy on nicotine dependence in the child is the result of some other contextual factors that were not addressed in this article. Ultimately, our data do not allow us to determine to what extent and by what mechanisms the observed mother-offspring associations are mediated. This issue warrants future research.

\section{Conclusions}

To our knowledge, this is the first study to prospectively examine the mother-child association of smoking in a community-based sample of adolescents for whom diagnostic information about smoking and nicotine dependence in both mothers and children was collected by independent diagnostic interviews. We have been able to show that the offspring of at least regularly smoking mothers are more likely to develop a more malignant course of smoking behavior and nicotine dependence when compared to the children of non-/occasionally smoking mothers. Further, maternal smoking during pregnancy seems to add an additional risk for these outcomes in the children, specifically for nicotine dependence. Our findings suggest that maternal smoking may be seen as an important marker of increased risk for smoking in both sons and daughters. They argue for specific intervention and prevention efforts in those children.

\section{Acknowledgements}

This work is part of the Early Developmental Stages of Psychopathology (EDSP) Study and is funded by the German Ministry of Research and Technology, project No. 01 EB 9405/6 and 01 EB 9901/6. Principal investigators are Dr. Hans-Ulrich Wittchen and Dr. Roselind Lieb. Current or former staff members of the EDSP group are: Dr. Kirsten von Sydow; Dr. Gabriele Lachner; Dr. Axel Perkonigg; Dr. Peter Schuster; Dr. Franz Gander; Dipl.-Stat. Michael Höfler; Dipl.-Psych. Holger Sonntag; Mag. phil. Esther Beloch; Dr. Martina Fuetsch; Dipl.-Psych. Elzbieta Garczynski; Dipl.-Psych. Alexandra Holly; Dr. Barbara Isensee; Dr. Marianne Mastaler; Dr. Chris Nelson; Dipl.-Inf. Hildegard Pfister; Dr. Victoria Reed; Dipl.Psych. Andrea Schreier; Dipl.-Psych. Dilek Türk; Dipl.-Psych. Antonia Vossen; Dr. Ursula Wunderlich, and Dipl.-Psych. Petra Zimmermann. Scientific advisors are Dr. Jules Angst (Zurich); Dr. Jürgen Margraf (Basel); Dr. Günther Esser (Potsdam); Dr. Kathleen Merikangas (NIMH, Bethesda, Md.), and Dr. Ron Kessler (Harvard, Boston, Mass.).

\section{References}

1 Sieber M, Angst J: Drogen-, Alkohol- und Tabakkonsum. Ein Beitrag zur Epidemiologie und Ätiologie bei jungen Erwachsenen. Bern, Huber, 1981

2 Russell M, Cooper ML, Frone MR: The influence of sociodemographic characteristics on familial alcohol problems: Data from a community sample. Alcohol Clin Exp Res 1990;14: 221-226.

3 Sher KJ, Walitzer KS, Wood PK, Brent EE: Characteristics of children of alcoholics: Putative risk factors, substance use and abuser, and psychopathology. J Abnorm Psychol 1991;100: 427-448.
4 Mathew RJ, Wilson WH, Blazer DG, George LK: Psychiatric disorders in adult children of alcoholics: Data from the Epidemiologic Catchment Area Project. Am J Psychiatry 1993; 150:793-800

5 Bidaut-Russell M, Bradford SE, Smith EM: Prevalence of mental illness in adult offspring of alcoholic mothers. Drug Alcohol Depend 1994;35:81-90.

6 Dierker LC, Merikangas KR, Szatmari P: Influence of parental concordance for psychiatric disorders on psychopathology in offspring. $\mathbf{J}$ Am Acad Child Adolesc Psychiatry 1999;38: 280-288.

7 Hill SY, Yuan H: Familial density of alcoholism and onset of adolescent drinking. J Stud Alcohol 1999;60:7-17.
8 Lieb R, Merikangas K, Höfler M, Pfister H, Isensee B, Wittchen H-U: Parental alcohol use disorders and alcohol use and disorders in offspring: A community study. Psychol Med 2002;32:63-78.

9 Reich W, Earls F, Frankel O, Shayka JJ: Psychopathology in children of alcoholics. J Am Acad Child Adolesc Psychiatry 1993;32:9951002.

10 Sher KJ, Gothman HJ, Erickson DJ, Wood PK: A prospective, high risk-study of the relationship between tobacco dependence and alcohol use disorders. Alcohol Clin Exp Res 1996;20:485-492. 
11 Windle M: Mate similarity, heavy substance use and family history of problem drinking among young adult women. J Stud Alcohol 1997;58:573-580.

12 Lieb R, Isensee B, Höfler M, Pfister H, Wittchen H-U: Elterliche Alkoholbelastung und die Entwicklung von Suchtproblemen bei ihren Kindern - Ergebnisse der prospektiv-longitudinalen EDSP-Studie. Suchttherapie 2001;2: 125-136.

13 Biederman J, Faraone SV, Monuteaux MC, Feighner JA: Patterns of alcohol and drug use in adolescents can be predicted by parental substance use disorders. Pediatrics 2000;106: 792-797.

14 Anthony JC, Warner LA, Kessler RC: Comparative epidemiology of dependence on tobacco, alcohol, controlled substances, and inhalants: Basic findings from the National Comorbidity Survey. Exp Clin Psychopharmacol 1994;2: 244-268.

15 Simon R, Tauscher M, Pfeiffer T: Suchtbericht Deutschland 1999. Hohengehren, Schneider, 1999.

16 Breslau N, Johnson EO, Hiripi E, Kessler R: Nicotine dependence in the United States Prevalence, trends, and smoking persistence. Arch Gen Psychiatry 2001;58:810-816.

17 Weitzman M, Gortmaker S, Sobol A: Maternal smoking and behavior problems of children. Pediatrics 1992;90:342-349.

18 Fergusson DM, Horwood LJ, Lynskey MT: Maternal smoking before and after pregnancy: Effects on behavioral outcomes in middle childhood. Pediatrics 1993;92:815-822.

19 Orlebeke J, Knol DL, Verhulst FC: Increase in child behavior problems resulting from maternal smoking during pregnancy. Arch Environ Health 1997;52:317-321.

20 Wakschlag LS, Lahey BB, Loeher R, Green SM, Gordon RA, Leventhal BL: Maternal smoking during pregnancy and the risk of conduct disorder in boys. Arch Gen Psychiatry 1997;54:670-676.

21 Fergusson DM, Woodward LJ, Horwood LJ: Maternal smoking during pregnancy and psychiatric adjustment in late adolescence. Arch Gen Psychiatry 1998;55:721-727.

22 Weissman MM, Warner V, Wickramaratne PJ Kandel DB: Maternal smoking during pregnancy and psychopathology in offspring followed to adulthood. J Am Acad Child Adolesc Psychiatry $1999 ; 38: 892-899$.

23 Brook JS, Brook DW, Whiteman M: The influence of maternal smoking during pregnancy on the toddler's negativity. Arch Pediatr Adol Med 2000; 154:381-385.

24 Hill SY, Lowers L, Locke-Wellman J, Shen S: Maternal smoking and drinking during pregnancy and the risk for child and adolescent psychiatric disorders. J Stud Alcohol 2000;61: 661-668.

25 Wasserman GA, Liu X, Pine DS, Graziano JH Contributions of maternal smoking during pregnancy and lead exposure to early child behavior problems. Neurotox Teratol 2001;23: 13-21.
26 Fox NL, Sexton M, Hebel JR: Prenatal exposure to tobacco. I. Effects on physical growth at age three. Intern J Epidemiol 1990;19:66-71.

27 Gilliland FD, Li Y-F, Peters M: Effects of maternal smoking during pregnancy and environmental tobacco smoke on asthma and wheezing in children. Am J Resp Crit Care Med 2001;163:429-436.

28 Tong S, McMichael AJ: Maternal smoking and neuropsychological development in childhood - A review of the evidence. Dev Med Child Neurol 1992;34:191-197.

29 MacArthur CM, Knox EG, Lancashire RJ: Effects at age nine of maternal smoking in pregnancy: Experimental and observational findings. Br J Obstet Gynaecol 2001;108:67-73.

30 Chassin L, Presson CC, Sherman SJ: Cigarette smoking and adolescent psychosocial development. Basic Appl Soc Psych 1984;5:295-315.

31 Chassin L, Presson CC, Sherman SJ, Montello $\mathrm{D}$, McGrew J: Changes in peer and parent influence during adolescence: Longitudinal versus cross-sectional perspectives on smoking initiation. Dev Psychol 1986;22:327-334.

32 Foshee V, Bauman KE: Parental and peer characteristics as modifiers of the bond-behavior relationship: An elaboration of control theory. J Health Soc Behav 1992;33:66-76.

33 Flay BR, Hu FB, Richardson J: Psychosocial predictors of different stages of cigarette smoking among high school students. Prevent Med 1998;27:A9-A18.

34 Flay BR, Hu FB, Siddiqui O, Day LE, Hedeker D, Petraitis J, Richardson J, Sussman S: Differential influence of parental smoking and friends' smoking on adolescent initiation and escalation of smoking. J Health Soc Behav 1994;35:248-265.

35 Kandel DB, Wu P, Davies M: Maternal smoking during pregnancy and smoking by adolescent daughters. Am J Publ Health 1994;84: 1407-1413.

36 Kandel DB, Udry JR: Prenatal effects of maternal smoking on daughters' smoking: Nicotine or testosterone exposure? Am J Publ Health 1999;89:1377-1383.

37 Kandel DB, Wu P: The contributions of mothers and fathers to the intergenerational transmission of cigarette smoking in adolescence. $\mathbf{J}$ Res Adolescence 1995;5:225-252.

38 Pederson LL, Koval JJ, O'Connor K: Are psychosocial factors related to smoking in grade- 6 students? Addict Behav 1997;22:169-181.

39 Jackson C, Henriksen L: Do as I say: Parent smoking, antismoking socialization, and smoking onset among children. Addict Behav 1997; 22:107-114

40 Griesler PC, Kandel DB, Davies M: Maternal smoking in pregnancy, child behavior problems, and adolescent smoking. J Res Adolesc 1998;8:159-185

41 Cornelius MD, Leech SL, Goldschmidt L, Day NL: Prenatal tobacco exposure: Is it a risk factor for early tobacco experimentation? Nicotine Tobacco Res 2000;2:45-52.

42 Eckhardt L, Woodruff SI, Elder JP: A longitudinal analysis of adolescent smoking and its correlates. J School Health 1994;64:67-72.
43 Rowe DC, Chassin L, Presson C, Sherman SJ: Parental smoking and the 'epidemic' spread of cigarette smoking. J Appl Soc Psychol 1996;26: 437-454.

44 Zhu S-H, Sun J, Billings SC, Choi WS, Malarcher A: Predictors of smoking cessation in US adolescents. Am J Prevent Med 1999;16: 202-207.

45 Ary DV, Biglan A: Longitudinal changes in adolescent cigarette smoking behavior: Onset and cessation. J Behav Med 1988;11:361-382.

46 Harrel JS, Bangdiwala SI, Deng SB, Webb JP Bradley C: Smoking initiation in youth - The role of gender, race, socioeconomics, and developmental status. J Adolesc Health 1998;23: 271-279.

47 Dierker LC, Avenevoli S, Merikangas KR, Flaherty BP, Stolar M: Association between psychiatric disorders and the progression of tobacco use behaviors. J Am Acad Child Adolesc Psychiatry 2001;40:1159-1167.

48 Wittchen H-U, Perkonigg A, Lachner G, Nelson CB: Early developmental stages of psychopathology study (EDSP): Objectives and design. Eur Addict Res 1998;4:18-27.

49 Lieb R, Isensee B, Sydow K von, Wittchen H-U: The Early Developmental Stages of Psychopathology Study (EDSP): A methodological update. Eur Addict Res 2000;6:170-182.

50 Wittchen H-U, Pfister H (eds): DIA-X-Interviews: Manual für Screening-Verfahren und Interview. Interviewheft Längsschnittuntersuchung (DIA-X-Lifetime); Ergänzungsheft (DIA-X-Lifetime); Interviewheft Querschnittuntersuchung (DIA-X-12 Monate); Ergänzungsheft (DIA-X-12 Monate); PC-Programm zur Durchführung des Interviews (Längs- und Querschnittuntersuchung); Auswertungsprogramm. Frankfurt, Swets \& Zeitlinger, 1997.

51 Lachner G, Wittchen H-U, Perkonigg A, Holly A, Schuster P, Wunderlich U, Türk D, Garczynski E, Pfister H: Structure, content and reliability of the Munich-Composite International Diagnostic Interview (M-CIDI). Substance use sections. Eur Addict Res 1998;4:2841.

52 Reed V, Gander F, Pfister H, Steiger A, Sonntag $\mathrm{H}$, Trenkwalder C, Hundt W, Wittchen H-U: To what degree the Composite International Diagnostic Interview (CIDI) correctly identifies DSM-IV disorders? Testing validity issues in a clinical sample. Int J Meth Psychiatr Res 1998;7:142-155.

53 Wittchen H-U, Lachner G, Wunderlich U, Pfister H, 1998: Test-retest reliability of the computerized DSM-IV version of the MunichComposite International Diagnostic Interview (M-CIDI). Soc Psychiatry Psychiatr Epidemiol 1998;33:568-578.

54 Höfler M, Lieb R, Perkonigg A, Schuster P, Sonntag H, Wittchen H-U: Covariates of cannabis use progression in a representative population sample of adolescents: A prospective examination of vulnerability and risk factors. Addiction 1999;94:1679-1694. 
55 Wittchen H-U, Lieb R, Schuster P, Oldehinkel $\mathrm{T}$ : When is onset? Investigations into early developmental stages of anxiety and depressive disorders; in Rapoport JL (ed): Childhood Onset of 'Adult' Psychopathology: Clinical and Research Advances. Washington, American Psychiatric Press, 1999, pp 259-302.

56 Nelson CB, Wittchen H-U: DSM-IV alcoho disorders in a general population sample of adolescents and young adults. Addiction 1998; 93:1065-1077.

57 Sonntag H, Wittchen H-U, Höfler M, Kessler RC, Stein MB: Are social fears and DSM-IV social anxiety disorder associated with smoking and nicotine dependence in adolescents and young adults. Eur Psychiatry 2000;15:67-74

58 StataCorp: Stata Statistical Software: Release 7.0. College Station, Stata, 2001.
59 Royall RM: Model Robust Confidence Intervals using Maximum Likelihood Estimators. Int Statist Rev 1986;54:221-226.

60 McCullagh P, Nelder JA: Generalized Linear Models, ed 2. London, Chapman \& Hall, 1989.

61 Fahrmeir A, Tutz G: Multivariate Statistical Modelling Based on Generalized Linear Models. Berlin, Springer, 1994.

62 Andersen PK, Keiding N: Survival analysis; in Armitage P, David HA (eds): Advances in Biometry - 50 Years of the International Biometric Society. New York, Wiley, 1996, pp 177-200.

63 Cox DR: Regression models and life tables (with discussion). J R Stat Soc 1972;34:187220.
64 Chassin L, Presson CC, Bensenberg M, Corty E, Olshavsky RW, Sherman SJ: Predicting adolescents' intentions to smoke cigarettes. J Health Soc Behav 1981;22:445-455.

65 Bauman KE, Botvin EM, Baker E: Normative expectations and the behavior of significant others: An integration of traditions in research on adolescents' cigarette smoking. Psychol Rep 1992;71:568-570.

66 Swan AV, Creeser R, Murray M: When and why children first start to smoke. Int J Epidemiol 1990;19:323-330.

67 Sullivan PF, Kendler KS: The genetic epidemiology of smoking. Nicotine Tobacco Res 1999; 1(suppl 2):S51-S57.

68 Mayhew KP, Flay BR, Mott JA: Stages in the development of adolescent smoking. Drug Alcohol Depend 2000;59(suppl 1):S61-S81. 